\title{
Recovery and screening for antibiotic susceptibility of potential bacterial pathogens from the oral cavity of shark species involved in attacks on humans in Recife, Brazil
}

Correspondence

N. T. Pontes-Filho

ntpf@gmail.com.br

J. V. Lima-Filho

jvitor@db.ufrpe.br

Received 9 March 2010

Accepted 20 April 2010

\author{
J. A. Interaminense, ${ }^{1}$ D. C. O. Nascimento, ${ }^{1}$ R. F. Ventura, ${ }^{1}$ J. E. C. Batista, ${ }^{1}$ \\ M. M. C. Souza, ${ }^{2}$ F. H. V. Hazin, ${ }^{2}$ N. T. Pontes-Filho ${ }^{3}$ and J. V. Lima-Filho ${ }^{1}$ \\ ${ }^{1}$ Departamento de Biologia, Universidade Federal Rural de Pernambuco, Recife, PE, Brazil \\ ${ }^{2}$ Departamento de Pesca e Aqüicultura, Universidade Federal Rural de Pernambuco, Recife, PE, \\ Brazil \\ ${ }^{3}$ Departamento de Patologia, Universidade Federal de Pernambuco, Recife, PE, Brazil
}

The number of incidents involving sharks and humans at beaches in Recife, on the north-eastern Brazilian coast, is among the highest worldwide. In addition, wound infections in survivors are common; but the nature and risk of the aetiological agents is unknown. In the present study, 81 potential bacterial pathogens were identified in the oral cavity of sharks involved in attacks in Recife, and were subjected to antibiotic susceptibility tests using the standardized disc-diffusion method. The majority were enterobacteria such as Enterobacter spp., Citrobacter spp., Proteus spp., Providencia alcalifaciens, Escherichia coli, Moellerella wisconcensis and Leclercia adecarboxylata. Other Gram-negative bacteria included Vibrio spp., Burkholderia cepacia, Acinetobacter spp. and Pseudomonas spp. In addition, coagulase-positive and coagulasenegative Staphylococcus spp., Enterococcus spp. and Micrococcus spp. were identified, besides Streptococcus spp. from the viridans group. Resistance was especially found in the Proteus mirabilis and Citrobacter freundii, and ranged from 4 to 6 antibiotics out of the 13 tested. Gentamicin and vancomycin were the most effective against Gram-positive cocci strains, whereas levofloxacin was fully inhibitory against Gram-positive and Gram-negative bacteria. These data are discussed in light of a retrospective evaluation of the medical records of three shark victims treated at Restauração Hospital in Recife.

\section{INTRODUCTION}

Attacks by sharks have resulted in fewer than 400 fatal victims around the world since records first started being kept in the early 1900s (International Shark Attack File - http://www.flmnh.ufl.edu/fish/Sharks/ISAF/ISAF.htm). However, from 1992 to 2009 in Recife, Brazil, sharks bit 53 people, of whom 20 died as a result of bleeding. The main victims have been surfers and swimmers who crossed over the natural barrier reefs running along the seashore. Two shark species have been reported as being mainly involved: the bull shark (Carcharhinus leucas) and the tiger shark (Galeocerdo cuvier) (Hazin et al., 2008), these species have also been related to attacks in Florida, South Africa and Australia (International Shark Attack File - http:// www.flmnh.ufl.edu/fish/Sharks/ISAF/ISAF.htm). Due to lacerations or amputations of superior and/or inferior members, survivors have been treated with massive

Abbreviation: CLSI, Clinical and Laboratory Standards Institute. antibiotic therapy to avoid wound infections (Caldicott et al., 2001). Nevertheless, the origin of contaminating micro-organisms is uncertain given that many species can be found in the oral cavity of sharks and in seawater.

The harmful potential of marine bacteria for human health has been reported, indicating many species are implicated in wound infections and seafood toxicity (Kueh et al., 1992; Howard \& Bennett, 1993). However, studies reporting potential bacterial pathogens in the oral cavity of sharks are rare. Previously, Buck et al. (1984) reported that Vibrio sp., Staphylococcus sp., Pseudomonas sp., Citrobacter sp. and Micrococcus sp. were recovered from a tooth of a great white shark (Carcharodon carcharias). Moreover, while polymicrobial infections are the main concern regarding shark victims, treatment is usually carried out with non-specific antibiotics since wound culture for antibiotic-susceptibility tests is not a routine hospital practice. For instance, Royle et al. (1997) reported that Aeromonas hydrophila, Proteus sp., Klebsiella oxytoca, Klebsiella pneumoniae, Citrobacter sp. and 
Vibrio alginolyticus were isolated from the wounds of a shark victim whose treatment changed over time and involved application of gentamicin, metronidazole and ciprofloxacin. This study illustrates the complexity of defining an appropriate antibiotic-schedule for shark victims. In the present study we screened bacterial isolates from the oral cavity of captured bull sharks and tiger sharks for antibiotic susceptibility to obtain data to support antibiotic therapies for shark victims.

\section{METHODS}

Shark capture. Sharks of two species related to attacks on humans (Carcharhinus leucas and Galeocerdo cuvier) were captured by the boat Sinuelo in an area stretching about $20 \mathrm{~km}$ off the Recife shoreline. Four bull sharks (Carcharhinus leucas) and five tiger sharks (Galeocerdo cuvier) were captured between 2006 and 2008 through the use of bottom longlines and drumlines. The longline consisted of a main multifilament polyamide line, $8 \mathrm{~mm}$ in diameter and $4 \mathrm{~km}$ in length, subdivided into 4 segments, each delimited by 2 buoys and containing 25 hooks, giving a total of 100 hooks. Secondary lines were also made of polyamide line, $8 \mathrm{~mm}$ in diameter and $8 \mathrm{~m}$ in length, culminating in two $11 \mathrm{~m}$ long steel gangions connected to a swivel and a hook at the end. Twenty drumlines were deployed in pairs and had a structure similar to those used in the longline. After microbiological collection, the animals were also used for several other biological studies to make greater use of them. All experiments followed the institutional policy of the animal ethics committee of Pernambuco Federal Rural University [Committee of Ethics in Animal Experimentation (CEUA)/Universidade Federal Rural de Pernambuco (UFRPE) protocol number 19.2009].

Bacterial sample collection and identification. Upon collection of microbial samples for each group of sharks the sample were pooled. Since microbiological procedures could not be carried out aboard the boat just after capture, the shark collectors were instructed not to cut open the animals' oral cavity to avoid environmental contamination. In addition, when the animals could not be taken to the laboratory on the same day as they were captured, they were frozen at $-18 \mathrm{C}$ until bacterial samples could be collected. Due to the animals' size, which reached $2.5 \mathrm{~m}$, in the laboratory sharks were manipulated on a decontaminated board near to a Bunsen burner. Separate sterile swabs were taken from the teeth and under the gums of the sharks and plated onto blood agar or used to inoculate brain heart infusion (BHI) broth (Oxoid) along with $3-5 \% \mathrm{NaCl}$ for culture of halophilic bacteria. After $24-48 \mathrm{~h}$ incubation at $35^{\circ} \mathrm{C}$, halophilic bacteria were cultured on TCBS (thiosulfate-citrate-bile salts-sucrose) agar (Oxoid) to search for Vibrio spp. or on BHI agar for staphylococci. The isolates were differentiated by colony morphology and Gram staining, and plated onto BHI agar or blood agar to check for purity. MacConkey agar, sulfite-bismuth agar and Salmonella-Shigella agar were used to investigate the presence of enterobacteria and cetrimide agar was used to investigate Pseudomonas sp. The bacterial identification was carried out with commercial kits, following the instructions of the manufacturer (bioMérieux). The API 20E kit was used for enterobacteriaceae, API Staph for staphylococci, API 20NE for non-fermenting bacteria and API CH50 for carbohydrate fermenting bacterial differentiation.

Antibiotic-susceptibility tests. Antibiotic-susceptibility tests were carried out by the standard disc-diffusion method, following the recommendations of the Clinical and Laboratory Standards Institute (CLSI), formerly the National Committee for Clinical Laboratory Standards (NCCLS, 2002). Briefly, filter paper discs $5 \mathrm{~mm}$ in diameter impregnated with antibiotics (Cecon) were added to cultures in Petri dishes ( 0.5 on the McFarland scale, corresponding to $10^{8}$ cells $\mathrm{ml}^{-1}$ ) containing Mueller-Hinton agar (Oxoid). After $24 \mathrm{~h}$ incubation at $35{ }^{\circ} \mathrm{C}$, the diameter of the inhibition zone was measured with a calliper. All tests were carried out in duplicate and the results were interpreted as sensitive, moderately sensitive or resistant.

The antibiotics tested in the present study were selected from among those used in hospital routine for primary and complementary tests. The breakpoints for resistance were those recommended by CLSI. The resistance rate was calculated as the number of non-susceptible isolates divided by the total number of isolates. Multidrug resistance among Gram-positive cocci strains was defined as resistance to penicillin and oxacillin plus at least three of the following agents: erythromycin, ciprofloxacin, gentamicin and tetracycline. Bacterial isolates obtained from a single sample and identified as belonging to the same species with an identical antibiotic resistance/sensitivity profile were treated as a single strain. In this case, bacterial replicates were not conducted.

Medical records. Data from the treatment records of three sharkattack survivors in Recife treated at Restauração Hospital were obtained after institutional approval of the hospital's ethics committee [Committee of Ethics in Research (CEP)/Restauração Hospital/protocol number FR199101]. Emphasis was given to data related to drug therapy.

\section{RESULTS AND DISCUSSION}

\section{Bacterial identification and antibiotic susceptibility}

The microbial isolates included Gram-positive as well as Gram-negative bacteria previously associated with different illnesses in humans, indicating the risk of polymicrobial infections in shark victims. Those strains commonly related to wound or soft-tissue infections, pyomyositis, osteomyelitis and bacteraemia are indicated in Table 1. As expected, some bacterial species found in the sharks' oral cavities have been reported in seawater. Since these animals naturally keep moving in order to force marine water across their gills to allow oxygen absorption, environmental water quality seems to be significant to the determination of the transitory or resident bacterial population in sharks' oral cavities. Although we could not confirm those bacterial strains belonged to a resident microbiota of sharks, the risk for human health was marked.

In the present study, 81 bacterial isolates with distinct antibiotic-susceptibility profiles were recovered from the oral cavity of bull sharks and tiger sharks. Tables 2 and 3 summarize the antibiotic-susceptibility profiles of the main isolates. There was a higher occurrence of members of the family Enterobacteriaceae (67.9\%), such as Enterobacter spp., Citrobacter spp., Proteus spp., Providencia alcalifaciens, Escherichia coli, Moellerella wisconcensis and Leclercia adecarboxylata, possibly related to the low water quality in the marine environment offshore from Recife (Table 2). However, antibiotic resistance was mainly found in Proteus mirabilis and Citrobacter freundii strains, and ranged from 
Table 1. Potential medical implications of bacterial strains from the oral cavity of bull sharks and tiger sharks for shark victims

Source: Koneman et al. (2001).

\begin{tabular}{|c|c|}
\hline Bacterial species & Medical implication \\
\hline Escherichia coli & $\begin{array}{l}\text { Wound infections, diarrhoea, septicaemia, septic shock, infections of urinary system, } \\
\text { pneumonia, meningitides and others }\end{array}$ \\
\hline Proteus mirabilis & Wound infections and infections of urinary system \\
\hline Vibrio parahaemolyticus & Wounds and soft-tissue infections, septicaemia \\
\hline Pseudomonas aeruginosa & Opportunistic infections of skin lesions, nosocomial infections \\
\hline Pseudomonas stutzerii & $\begin{array}{l}\text { Wound infections of traumatic lesions, otitis media, conjunctivitis, pneumonia, septic } \\
\text { arthritis, endocarditis, meningitides }\end{array}$ \\
\hline Staphylococcus hominis & Bacteraemia \\
\hline Streptococcus from viridans group & Isolated from severe infections in immunocompromised patients \\
\hline Enterococcus sp. & $\begin{array}{l}\text { Soft-tissue infections, community-acquired and nosocomial infections, urinary infections, } \\
\text { bacteraemia, endocarditis, intra-abdominal infections, sepses, meningitides }\end{array}$ \\
\hline
\end{tabular}

4 to 6 antibiotics out of 13 indicated by CLSI. Proteus mirabilis is widely reported as an opportunistic agent infecting wounds and causing urinary infections, whereas Citrobacter freundii is related to diarrhoea episodes and extra-intestinal infections (Wang et al., 2000; Sabbuba et al., 2003). In addition, our data showed $20 \%$ of Proteus mirabilis were resistant to imipenem, a drug frequently employed successfully against Gram-negative nosocomial infections. However, sensitivity of Citrobacter freundii strains to cephalosporins and carbapenems has also been described for nosocomial isolates (Sabbuba et al., 2003). The non-fermenting Gram-negative bacteria, such as Pseudomonas stutzerii (one isolate) from the bull sharks, and Burkholderia cepacia (one isolate), Acinetobacter spp. (two isolates) and Pseudomonas aeruginosa (two isolates) along with Vibrio parahaemolyticus (one isolate) and Vibrio sp. (one isolate) from the tiger sharks, were all sensitive to the majority of antibiotics tested (data not shown). However, attention should be paid to Pseudomonas aeruginosa, which is reported in many international studies due to its incidence in nosocomial infections (Gales et al., 2009). Moreover, Vibrio species such as V. alginolyticus, Vibrio fluvialis, V. parahaemolyticus and Vibrio carchariae have been associated with soft-tissue and wound infections, and septicaemia (Schmidt et al., 1979; Pavia et al., 1989; Huang \& Hsu, 2005; Han et al., 2007) (Table 3).

Gram-positive cocci strains included the coagulase-positive as well as coagulase-negative Staphylococcus spp., Enterococcus sp., Streptococcus spp. and Micrococcus spp. Streptococcus sp. isolates were catalase-negative, resistant to optochin and $\alpha$-haemolytic in blood agar, and were identified as belonging to the viridans group (Table 3 ). Our data showed no multidrug resistance among Grampositive cocci strains, but the occurrence of oxacillin plus penicillin-resistant staphylococci suggested some strains bear the mecA gene, which confers resistance to several $\beta$ lactam antibiotics (Volkmann et al., 2004). Staphylococcus aureus, Staphylococcus epidermidis, $\alpha$ - and $\beta$-haemolytic Streptococcus are broadly related to infections of wounds received in the marine environment (Isbister \& Caldicott, 2004). The medical implications of staphylococci infections are serious because of the large number of strains recognized as being human pathogens (Stepanovic et al., 2005). A particular concern is the emergence of necrotizing soft-tissue infections caused by antibiotic-resistant streptococci from the viridans group despite the variation of penicillin-fixing proteins in the bacterial cell membrane (Cattaneo et al., 2010). However, the Streptococcus spp., Enterococcus spp. and Micrococcus spp. from the sharks were all sensitive to several antibiotics. Although Micrococcus spp. are usually described as non-pathogenic micro-organisms, clinical isolates have been reported as agents of opportunistic infections (von Eiff et al., 1995).

\section{Case reports}

Patient 1. The patient was an 18-year-old male attacked in the leg. The member was amputated at the upper thigh. Antibiotic therapy started with intravenous ceftriaxone ( $1 \mathrm{~g}$ every $12 \mathrm{~h}$ ) and metronidazole ( $1 \mathrm{~g}$ every $8 \mathrm{~h}$ ) for 7 
Table 2. Antibiotic susceptibility of enterobacteria from the oral cavity of tiger sharks and bull sharks captured in Recife, Brazil

The multiresistance of a single strain among isolates of one bacterial species is indicated by underlining.

\begin{tabular}{|c|c|c|c|c|c|c|c|c|c|c|c|c|c|c|c|c|c|c|c|c|c|c|c|c|c|c|c|c|c|c|c|c|c|c|}
\hline & \multirow{3}{*}{$\begin{array}{c}\text { Total } \\
\text { no. of } \\
\text { isolates }\end{array}$} & \multicolumn{33}{|c|}{ Antibiotic $^{\star} \dagger$} \\
\hline & & \multicolumn{3}{|c|}{ AMP } & \multicolumn{3}{|c|}{ AMI } & \multicolumn{3}{|c|}{ GEN } & \multicolumn{3}{|c|}{ EST } & \multicolumn{3}{|c|}{ CIP } & \multicolumn{2}{|c|}{ LVX } & \multicolumn{2}{|c|}{ CLO } & \multicolumn{3}{|c|}{$\mathrm{CAZ}$} & \multicolumn{2}{|c|}{ CFL } & \multicolumn{2}{|c|}{ AMC } & \multicolumn{3}{|c|}{ IMP } & \multicolumn{2}{|c|}{ TET } & \multicolumn{2}{|c|}{ ATM } \\
\hline & & $S$ & I & $\mathbf{R}$ & $S$ & $\mathbf{I}$ & $\mathbf{R}$ & $S$ & I & $\mathbf{R}$ & $S$ & I & $\mathbf{R}$ & $S$ & $\mathbf{I}$ & $\mathbf{R}$ & $S$ & I I & $S$ & I $\mathrm{r}$ & R $\quad S$ & I & $\mathbf{R}$ & $S$ & I I & $S$ & I R & R $\quad S$ & I & $\mathbf{R}$ & $S$ & I $\mathbf{R}$ & $S$ & I $\mathbf{R}$ \\
\hline \multicolumn{35}{|l|}{ Tiger shark } \\
\hline $\begin{array}{l}\text { Enterobacter } \\
\text { cloacae }\end{array}$ & 6 & 2 & 0 & $\underline{4}$ & 6 & 0 & 0 & 5 & 0 & $\underline{1}$ & 6 & 0 & 0 & 6 & 0 & 0 & 6 & 0 & 6 & 00 & 6 & 0 & 0 & 2 & 0 & 2 & 13 & $\begin{array}{ll}3 & 6\end{array}$ & 0 & 0 & 1 & $2 \underline{3}$ & 5 & $\begin{array}{ll}0 & 1\end{array}$ \\
\hline $\begin{array}{l}\text { Enterobacter } \\
\text { aerogenes }\end{array}$ & 2 & 0 & 0 & $\underline{2}$ & 2 & 0 & 0 & 2 & 0 & 0 & 1 & 1 & 0 & 2 & 0 & 0 & 2 & 0 & 2 & 00 & $0 \quad 2$ & 0 & 0 & 0 & 02 & 0 & $0 \underline{2}$ & 2 & 0 & 0 & 0 & $1 \underline{1}$ & 2 & 00 \\
\hline Citrobacter freundii & 5 & 2 & 1 & 2 & 5 & 0 & 0 & 4 & 0 & 1 & 4 & $\mathrm{NT} \ddagger \mathrm{N}$ & NT末 & 4 & 0 & $\underline{1}$ & 5 & 0 & 5 & 00 & $0 \quad 5$ & 0 & 0 & 0 & 05 & 1 & $1 \underline{3}$ & $\begin{array}{ll}3 & 5\end{array}$ & 0 & 0 & 2 & $0 \underline{3}$ & 4 & $0 \underline{1}$ \\
\hline Citrobacter koseri & 2 & 0 & 0 & 2 & 2 & 0 & 0 & 2 & 0 & 0 & 2 & 0 & 0 & 2 & 0 & $\overline{0}$ & 2 & 0 & 2 & $0 \quad 0$ & $0 \quad 2$ & 0 & 0 & 2 & 0 & 2 & 00 & $\begin{array}{ll}0 & 2\end{array}$ & 0 & 0 & 1 & $1 \overline{0}$ & 2 & $0 \overline{0}$ \\
\hline Proteus mirabilis & 6 & 1 & 0 & $\underline{5}$ & 5 & 1 & 0 & 6 & 0 & 0 & 1 & NT末 1 & NT末 & 6 & 0 & 0 & 6 & 0 & 2 & $0 \underline{4}$ & $\underline{4} \quad 4$ & 0 & 2 & 3 & 03 & 3 & 03 & 34 & 0 & $\underline{2}$ & 0 & $0 \underline{6}$ & 4 & 02 \\
\hline $\begin{array}{l}\text { Moellerella } \\
\text { wisconcensis }\end{array}$ & 2 & 2 & 0 & 0 & 2 & 0 & 0 & 2 & 0 & 0 & 2 & 0 & 0 & 2 & 0 & 0 & 2 & 0 & 2 & 00 & $0 \quad 2$ & 0 & 0 & 2 & 0 & 2 & $\begin{array}{ll}0 & 0\end{array}$ & $0 \quad 2$ & 0 & 0 & 1 & 10 & 2 & 00 \\
\hline $\begin{array}{l}\text { Providencia } \\
\text { alcalifaciens }\end{array}$ & 2 & 2 & 0 & 0 & 2 & 0 & 0 & 1 & 0 & 1 & 1 & 0 & 1 & 2 & 0 & 0 & 2 & 0 & 1 & 01 & 2 & 0 & 0 & 0 & 1 & 1 & $\begin{array}{lll}0 & 1\end{array}$ & 12 & 0 & 0 & 1 & $\begin{array}{ll}0 & 1\end{array}$ & 2 & 00 \\
\hline $\begin{array}{l}\text { Escherichia coli } \\
\text { Bull shark }\end{array}$ & 1 & 1 & 0 & 0 & 1 & 0 & 0 & 1 & 0 & 0 & 0 & 1 & 0 & 1 & 0 & 0 & 1 & 0 & 1 & 00 & 1 & 0 & 0 & 0 & 0 & 1 & $\begin{array}{ll}0 & 0\end{array}$ & $\begin{array}{ll}0 & 1\end{array}$ & 0 & 0 & 0 & 10 & 1 & 00 \\
\hline $\begin{array}{l}\text { Enterobacter } \\
\text { cloacae }\end{array}$ & 2 & 1 & 1 & 0 & 2 & 0 & 0 & 2 & 0 & 0 & 1 & $\mathrm{NT} \neq \mathrm{N}$ & NT末 & 2 & 0 & 0 & 2 & 0 & 2 & $0 \quad 0$ & 2 & 0 & 0 & 0 & 02 & 0 & 11 & 2 & 0 & 0 & 0 & 20 & 2 & 00 \\
\hline Citrobacter freundii & 5 & 2 & 1 & $\underline{2}$ & 5 & 0 & 0 & 4 & 0 & $\underline{1}$ & 3 & $\mathrm{NT} \ddagger \mathrm{N}$ & NT $\neq$ & 5 & 0 & 0 & 5 & 0 & 5 & $0 \quad 0$ & 5 & 0 & 0 & 1 & $0 \leq$ & 2 & $0 \underline{3}$ & 5 & 0 & 0 & 0 & $1 \underline{4}$ & 5 & 00 \\
\hline Citrobacter farmeri & 1 & 1 & 0 & 0 & 1 & 0 & 0 & 1 & 0 & 0 & 1 & 0 & 0 & 1 & 0 & 0 & 1 & 0 & 1 & 00 & 1 & 0 & 0 & 0 & 1 & 1 & $\begin{array}{ll}0 & 0\end{array}$ & 1 & 0 & 0 & 1 & 00 & 1 & 00 \\
\hline Proteus mirabilis & 14 & 3 & 0 & 11 & 14 & 0 & 0 & 12 & 0 & 2 & 4 & NT末 & 1 & 9 & 0 & $\underline{5}$ & 14 & 0 & $0 \quad 10$ & $0 \underline{4}$ & $\underline{4} \quad 14$ & 0 & 0 & 11 & 3 & 2 & $0 \underline{12}$ & $12 \quad 12$ & 0 & 2 & 0 & $0 \underline{14}$ & $4 \quad 14$ & 00 \\
\hline Proteus vulgaris & 6 & 2 & 1 & $\overline{3}$ & 6 & 0 & 0 & 6 & 0 & 0 & 6 & 0 & 0 & 6 & 0 & $\overline{0}$ & 6 & 0 & 5 & 10 & $\begin{array}{ll}0 & 6\end{array}$ & 0 & 0 & 2 & 0 & 5 & $1 \overline{0}$ & $\begin{array}{ll}0 & 6\end{array}$ & 0 & 0 & 2 & $2 \overline{2}$ & 6 & $\begin{array}{ll}0 & 0\end{array}$ \\
\hline $\begin{array}{l}\text { Leclercia } \\
\text { adecarboxylata }\end{array}$ & 1 & 1 & 0 & 0 & 1 & 0 & 0 & 1 & 0 & 0 & 1 & 0 & 0 & 1 & 0 & 0 & 1 & 0 & 1 & 00 & 1 & 0 & 0 & 0 & 0 & 1 & $\begin{array}{ll}0 & 0\end{array}$ & $\begin{array}{ll}0 & 1\end{array}$ & 0 & 0 & 0 & 10 & 1 & $\begin{array}{ll}0 & 0\end{array}$ \\
\hline $\begin{array}{l}\text { General } \\
\text { resistance rate } \S\end{array}$ & 55 & $56.3 \%$ & & & $0 \%$ & & & $10.9 \%$ & & & $5.4 \%$ & & & $10.9 \%$ & & & $0 \%$ & & $16.3 \%$ & & $3.6 \%$ & & & $49.1 \%$ & & $50.9 \%$ & & $7.2 \%$ & & & $1.8 \%$ & & $7.2 \%$ & \\
\hline
\end{tabular}

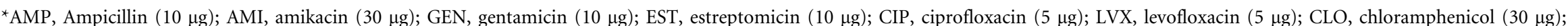
CAZ, ceftazidime $(30 \mu \mathrm{g})$; CFL, cefalotin $(30 \mu \mathrm{g})$; AMC, amoxicillin + clavulanic acid $(10 \mu \mathrm{g})$; IPM, imipenem $(10 \mu \mathrm{g})$; TET, tetracycline $(30 \mu \mathrm{g})$; ATM, aztreonam $(30 \mu \mathrm{g})$.

$\dagger$ The number of isolates sensitive (S), intermediately sensitive (I) or resistant (R) for each antibiotic for each bacterial species is shown.

$\ddagger$ Antibiotic not tested (NT) against the remaining isolates of such bacterial species.

$\S$ General resistance rate is given by the number of non-susceptible isolates divided by the total number of isolates submitted to antibiogram tests. 
Table 3. Antibiotic susceptibility of Gram-positive cocci isolates from the oral cavity of tiger sharks and bull sharks captured in Recife, Brazil

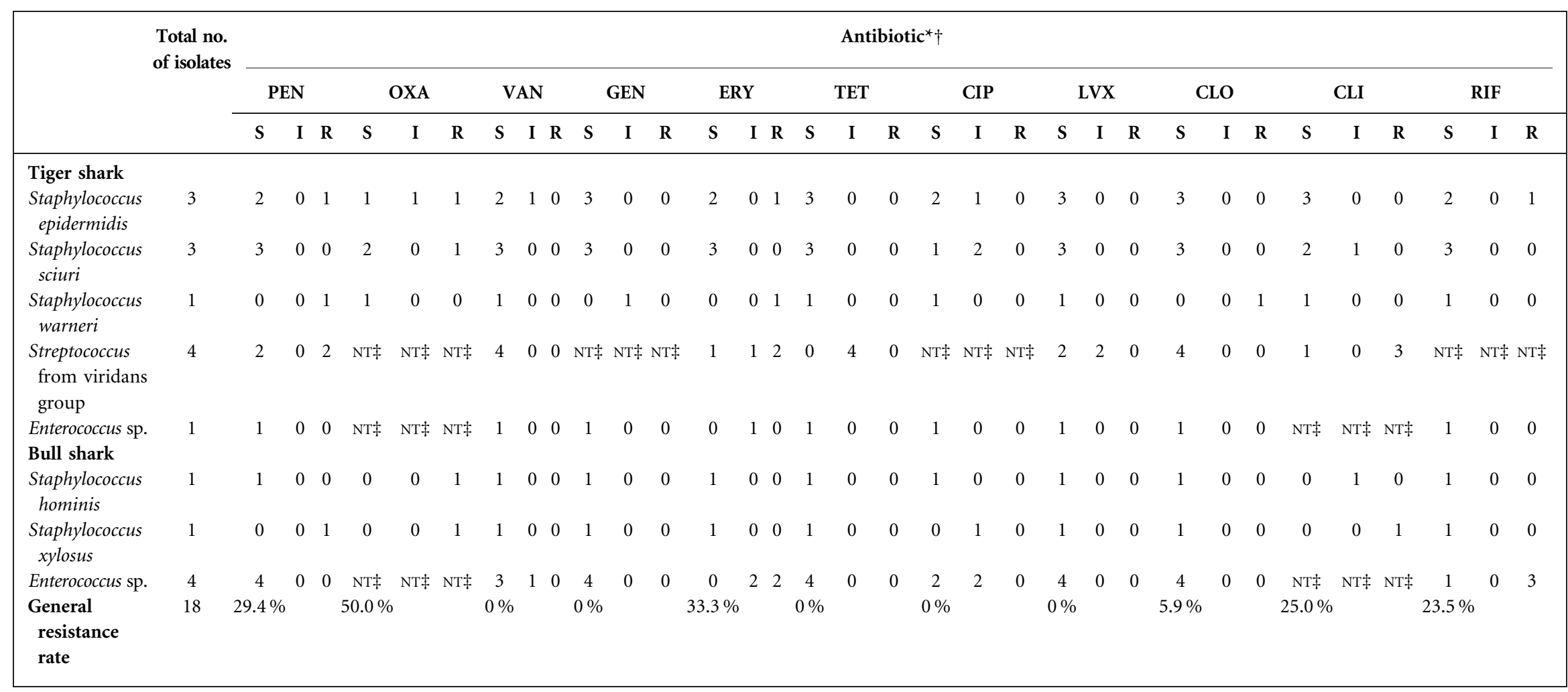

${ }^{*}$ PEN, Penicillin G $(10 \mu \mathrm{g})$; OXA, oxacillin $(1 \mu \mathrm{g})$; VAN, vancomycin $(30 \mu \mathrm{g})$; GEN, gentamicin $(10 \mu \mathrm{g})$; ERY, erythromycin $(15 \mu \mathrm{g})$; TET, tetracycline $(30 \mu \mathrm{g})$; CIP, ciprofloxacin $(5 \mu \mathrm{g})$; LVX, levofloxacin $(5 \mu \mathrm{g})$; CLO, chloramphenicol ( $30 \mu \mathrm{g})$; CLI, clindamycin $(2 \mu \mathrm{g})$; RIF, rifampicin $(5 \mu \mathrm{g})$.

$\dagger$ The number of isolates sensitive (S), intermediately sensitive (I) or resistant (R) for each antibiotic for each bacterial species is shown.

‡NT, Antibiotic not tested (NT) against such isolates. 
days. Then, metronidazole was suspended and treatment with intravenous ceftriaxone (500 mg every $12 \mathrm{~h}$ ) followed. Fever or wound infection was not reported during treatment. Blood culture was carried out but no microorganisms were identified. The patient was released from the hospital after 43 days.

Patient 2. The patient was a 14-year-old male attacked in the left calf. Antibiotic treatment started with intravenous ciprofloxacin (400 mg every $12 \mathrm{~h}$ ) and clindamycin (600 mg every $8 \mathrm{~h}$ ) for 15 days. After this, clindamycin was suspended and oral treatment with ciprofloxacin $(500 \mathrm{mg}$ every $12 \mathrm{~h}$ ) was maintained until the patient was released from the hospital 30 days later. During the treatment, he suffered from persistent fever, but blood culture was not reported.

Patient 3. The patient was a 14-year-old male attacked in the gluteus and right hand. Antibiotic treatment started with clindamycin $(600 \mathrm{mg}$ every $8 \mathrm{~h})$ and ciprofloxacin (400 mg every $12 \mathrm{~h}$ ). After 30 days, treatment with meropenem ( $1 \mathrm{~g}$ every $8 \mathrm{~h}$ ) was implemented for 23 days. The patient presented with fever, and cultures from blood, urine and fragments of the sacrum were identified as containing Pseudomonas aeruginosa, which was reported as resulting from nosocomial infection. Wound infection was reported in the gluteus after reconstructive surgery. Culture of abscess material identified Klebsiella sp. and Escherichia coli, whereas culture of the secretions identified these bacterial species and Pseudomonas aeruginosa. Antibioticsusceptibility tests revealed that the Klebsiella sp. was resistant to 8 out of 11 antibiotics, Escherichia coli was resistant to 7 out of 12 antibiotics and Pseudomonas aeruginosa was resistant to 5 out of 8 antibiotics. All the bacteria were susceptible to meropenem. The patient was released from the hospital after 78 days.

\section{Conclusions}

Evaluation of the medical records of the shark victims treated at Restauração Hospital showed that the extent of lesions was the main determining factor for bacterial colonization. In addition, the wound culture of one patient showed Pseudomonas aeruginosa and Escherichia coli, also identified in the oral cavity of the tiger sharks. The efficacy of the combined therapy varied among treatments as an adequate clinical response, but seemed to be determinant on control of polymicrobial infections as shown for patient 3. However, our data showed that preventive antibiotic therapy could start with a single drug, such as levofloxacin, which was inhibitory against Gram-positive and Gramnegative bacteria from sharks (Tables 2 and 3). Currently antibiotic therapy for shark victims treated at Restauração Hospital includes clindamycin for prevention of Grampositive infections and ciprofloxacin for the remaining bacterial strains. A retrospective study showed that among 795 patients with skin or soft-tissue infections, $94 \%$ were successfully treated with ciprofloxacin (Parish et al., 1990). Our data showed that $33 \%$ of Gram-positive cocci strains were resistant to clindamycin and $10.9 \%$ of the enterobacteria were resistant to ciprofloxacin. Otherwise, gentamicin and tetracycline plus ciprofloxacin and vancomycin were fully effective against cocci strains, and could be useful against Gram-positive infections. Likewise, levofloxacin and amikacin could be a reliable alternative instead of ciprofloxacin for shark victims.

In conclusion, our study is indicative that special attention should be given to the prevention and management of Gram-negative bacterial infections in shark victims. Accordingly, assessment of antibiogram data is crucial to provide relevant information for making a medical decision on treatment and the appropriate antibiotic for shark victims.

\section{ACKNOWLEDGEMENTS}

The authors thank the Pernambuco State Research Foundation (FACEPE) for funding, and Restauração Hospital for support on access to medical records of shark victims. Professor Lima-Filho received a scholarship support from Programa de Educação Tutorial (PET) (Brazilian Ministry of Education). Sponsorships: this study was funded by the Pernambuco State Research Foundation (FACEPE).

\section{REFERENCES}

Buck, J. D., Spotte, S. \& Gadbaw, J. J. (1984). Bacteriology of the teeth from a great white shark: potential medical implications for shark bite victims. J Clin Microbiol 20, 849-851.

Caldicott, D. G. E., Mahajani, R. \& Kuhn, M. (2001). The anatomy of a shark attack: a case report and review of the literature. Injury 32, 445453.

Cattaneo, C., Casari, S., Bracchi, F., Signorini, L., Ravizzola, G., Borlenghi, E., Re, A., Manca, N., Carosi, G. \& Rossi, G. (2010). Recent increase in enterococci, viridans streptococci, Pseudomonas spp. and multiresistant strains among haematological patients, with a negative impact on outcome. Results of a 3-year surveillance study at a single institution. Scand J Infect Dis 42, 324-332.

Gales, A. C., Sader, H. S., Ribeiro, J., Zoccoli, C., Barth, A. \& Pignatari, A. C. (2009). Antimicrobial susceptibility of gram-positive bacteria isolated in Brazilian hospitals participating in the SENTRY Program (2005-2008). Braz J Infect Dis 13, 90-98.

Han, F., Walker, R. D., Janes, M. E., Prinyawiwatkul, W. \& Ge, B. (2007). Antimicrobial susceptibility of Vibrio parahaemolyticus and Vibrio vulnificus from Louisiana gulf and retail raw oysters. Appl Environ Microbiol 73, 7096-7098.

Hazin, F. H. V., Burgess, G. H. \& Carvalho, F. C. (2008). A shark attack outbreak off Recife, Pernambuco, Brazil: 1992-2006. Bull Mar Sci 82, 199-212.

Howard, R. J. \& Bennett, N. T. (1993). Infections caused by halophilic marine vibrio bacteria. Ann Surg 217, 525-530.

Huang, K.-C. \& Hsu, R. W.-W. (2005). Vibrio fluvialis hemorrhagic cellulitis and cerebritis. Clin Infect Dis 40, e75-e77.

Isbister, G. K. \& Caldicott, D. G. (2004). Trauma and Envenomations from Marine Fauna. In Emergency Medicine: a Comprehensive Study Guide. Irving, TX: American College of Emergency Physicians. 
Koneman, E. W., Allen, S. D., Janda, W. M., Schreckenberger, P. C. \& Winn, W. C., Jr (2001). Diagnóstico Microbiológico. Rio de Janeiro, Brazil: Medsi.

Kueh, C. S., Kutarski, P. \& Brunton, M. (1992). Contaminated marine wounds - the risk of acquiring acute bacterial infection from marine recreational beaches. J Appl Bacteriol 73, 412-420.

NCCLS (2002). Performance Standards for Antimicrobial Disk Susceptibility Tests, approved standard, M2-A8. Villanova, PA: National Committee for Clinical Laboratory Standards.

Parish, L. C., Witkowski, J. A., Jungkind, D. L. \& Asper, R. F. (1990). Tratamento de infecções cutâneas. Experiência internacional com ciprofloxacina. An Bras Dermatol 65, 43-44.

Pavia, A. T., Bryan, J. A., Maher, K. L., Hester, T. R., Jr \& Farmer, J. J., III (1989). Vibrio carchariae infection after a shark bite. Ann Intern Med 111, 85-86.

Royle, J. A. M. B., Isaacs, D. M. D., Eagles, G. M. B., Cass, D. M. D., Gilroy, N. M. B., Chen, S. M. B., Malouf, D. M. B. \& Griffiths, C. A. M. (1997). Infections after shark attacks in Australia. Pediatr Infect Dis $J$ $16,531-532$.
Sabbuba, N. A., Mahenthiralingam, E. \& Stickler, D. J. (2003). Molecular epidemiology of Proteus mirabilis infections of the catheterized urinary tract. J Clin Microbiol 41, 4961-4965.

Schmidt, U., Chmel, H. \& Cobbs, C. (1979). Vibrio alginolyticus infections in humans. J Clin Microbiol 10, 666-668.

Stepanovic, S., Dakic, I., Morrison, D., Hauschild, T., Jezek, P., Petras, P., Martel, A., Vukovic, D., Shittu, A. \& Devriese, L. A. (2005). Identification and characterization of clinical isolates of members of the Staphylococcus sciuri group. J Clin Microbiol 43, 956-958.

Volkmann, H., Schwartz, T., Bischoff, P., Kirchen, S. \& Obst, U. (2004). Detection of clinically relevant antibiotic-resistance genes in municipal wastewater using real-time PCR (TaqMan). J Microbiol Methods 56, 277-286.

von Eiff, C., Herrmann, M. \& Peters, G. (1995). Antimicrobial susceptibilities of Stomatococcus mucilaginosus and of Micrococcus spp. Antimicrob Agents Chemother 39, 268-270.

Wang, J. T., Chang, S. C., Chen, Y. C. \& Luh, K. T. (2000). Comparison of antimicrobial susceptibility of Citrobacter freundii isolates in two different time periods. J Microbiol Immunol Infect 33, 258-262. 